\title{
Confesiones de conversión. Dolor, valor y cultura
}

\author{
RICARDO SANMARTÍN ARCE \\ Departamento de Antropología Social \\ Facultad de CC. Políticas y Sociología \\ Universidad Complutense. Madrid
}

Una de las preocupaciones del quehacer antropológico es siempre la fiabilidad de la etnografía: que aquel conjunto de relatos y observaciones que vamos acumulando a lo largo del trabajo de campo responda a lo que efectivamente embarga la vida real de los actores e informantes, de modo que desde toda esa etnografía podamos tener un acceso correcto, y lo menos erróneo posible, a los contenidos culturales y humanos de aquellos sobre quienes trabajamos. Una de las maneras de procurar que la etnografía tenga tal calidad es, obviamente, facilitar a los informantes una situación de seguridad y confianza en la interacción y en la conversación de modo que se expresen con sinceridad, aunque esto no garantice la ausencia de error o desinformación en el informante. Otra, más difícil pero que mejora siempre la calidad de la etnografía, es tratar con ellos temas vitales, problemas humanos reales y lo menos triviales posible. El problema está en que esta etnografía, de calidad por su rico contenido humano, nos pide que dirijamos nuestra atención hacia un tipo de vivencias de los actores cuyo estudio resulta siempre mucho más difícil de realizar. No quisiera con esto suponer que la etnografía "más fácil" sea menos fiable, pero sí suele resultar menos relevante. Aunque es obvio, siempre tropezamos con esa proporcionalidad directa existente entre la dificultad etnográfica y su relevancia antropológica. A uno de esos tipos de documentación etnográfica quisiera referirme en lo que sigue: las confesiones y, en especial, a las confesiones de conversión.

Quisiera apreciar su relevancia no por su frecuencia sino más bien por su escasez, por esa rareza que puede erguirse como contraste iluminador en la larga duración de toda crisis que no acabe de salir de sí misma produciendo finalmente un cambio, una transformación. En la conversión sucede justo lo contrario. Es el final de una crisis que desemboca en una profunda transformación e inicia un cambio de etapa en la vida del converso. Lo que a éste le sucede, los valores que enfatiza y usa como guía para penetrar en el conocimiento de la crisis que sufre, la versión que, 
según su época, da de ellos el converso, etc., todo ello nos está iluminando a la contra no sólo su anterior existencia, sino también la de todo aquel frente al cual el converso o es un traidor o una mera excepción o rareza. Aunque sólo fuera por eso, el estudio de las confesiones resultaría una fuente histórica de indudable interés.

Desde ese punto de vista las confesiones de conversión son documentos que, si bien no han sido creados a instancia del investigador, reúnen esas dos características: densidad humana y autenticidad, que facilitan la calidad de la etnografía. Con todo, la forma escrita que finalmente adop$\tan$ no es uniforme. Podemos encontrar una gran variedad de situaciones mixtas o intermedias desde el ensayo filosófico a la autobiografía, pasando por una desperdigada y repetida escritura en un conjunto de cartas a distintos interlocutores. Ya en el inicio del género las Confesiones de S. Agustín son una figura híbrida y original cuya difícil clasificación encaja mejor en una nueva categoría: la confesión como tal. Obviamente no toda autobiografía, carta o ensayo contiene una confesión propiamente dicha. Más bien son estos los tipos de escritura que acaban recibiendo, como depositarios o vehículos, el vertido humano de una confesión. Porque la confesión, como con tanto acierto entendió María Zambrano, más que un discurso "es una acción, la máxima acción que es dado ejecutar con la palabra" ${ }^{1}$, y esa acción puede apoyarse en muy distintos textos. Como tal acción su valor etnográfico no reside tanto en la exhaustividad biográfica de lo relatado, ni en la precisión de los detalles. Algunas de ellas, como la de Ignacio de Loyola, contienen errores incluso en las fechas; otras, como la Vida de Teresa de Ávila, van y vienen en el tiempo sin seguir un único y riguroso progreso lineal, o recogen sólo una parte de la propia biografía, como también es el caso de Viktor E. Frankl o de André Frossard. Su valor etnográfico reside en el testimonio que aporta sobre el dolor moral y su curación, sobre la complejidad del interior del hombre, sobre la tensión entre ruptura y continuidad de la identidad, sobre la estrecha relación entre valor y conocimiento, sobre la fuerza avasalladora con la que irrumpe en la experiencia una sorprendente vivencia que impone su verdad a quien la sufre y que levanta preguntas sobre el conocimiento y las creencias en quien lo estudia.

La confesión, similar y distinta entre los demás géneros de escritura, es también historia y literatura, aunque no sólo sea eso ni lo sea plena-

1 M. Zambrano, La Confesión: Género Literario (Madrid: Mondadori España, 1988), p. 18 [1943]. «Un acto, un solo acto de ardiente caridad, de húmedo afecto, de amor verdadero, y estoy salvo. Pero ¿qué me llevará á ese acto si ya no hay más que conceptos en mi espíritu? No puedo llorar. ¡Actos, actos, actos!n, clamaba Unamuno en su Diario intimo (Madrid: Alianza, 1996), p. 24. 
mente. Si bien, como señalaba, su valor etnográfico no reside en la exactitud de los detalles, cada confesión no sólo nos informa de un acontecimiento central en la historia del converso. De hecho en un buen número de confesiones el autor repasa en la memoria su propia biografía e incluye inevitables referencias a los hechos de la historia que han operado como circunstancias condicionantes y reveladoras del sentido de algunos de sus pasos. La confesión, pues, aunque no esté escrita con intención historiográfica, es sin duda una de las fuentes más útiles para historiar la intimidad. Pero ¿qué cualidades tiene que le hagan similar a la literatura?

A primera vista parece que no debiera caber duda alguna en cuanto a la ausencia de propósitos literarios explícitos en quienes vierten el relato de su conversión en una confesión escrita. Más allá de la corrección propia de un texto inteligible para el destinatario, lo que al autor le preocupa y mueve a la hora de redactar tal tipo de texto es apresar con precisión aquella sorprendente experiencia, de modo que el hecho de la redacción le ayude a él mismo a comprenderla. A esa auto-ayuda que en el espejo de papel busca el converso, diciendo las cosas para llegar a saberlas al decirlas, se suma en muchos casos la del interlocutor a distancia a quien se le escribe la carta que contiene la confesión. Simone Weil, M. García Morente y Carlos de Foucauld son algunos de los que han confesado su conversión a través de cartas a distintos amigos, confesores o directores espirituales. El mismo Foucauld, Julien Green o Unamuno redactan confesiones en sus diarios. En cualquier caso, en cartas o en diarios, la intimidad del medio elegido excluye la expectativa de una posible publicación y de un público lector que tan presentes están en el teatro o en la novela. Pero hay otros géneros en la literatura como la poesía, en la que esa anticipación de un posible lector apenas pesa en el autor o llega a ser un verdadero obstáculo para su producción, y a la que podría parecerse más el relato de cualquier confesión. Con todo, otras confesiones aparecen solapadas o simbolizadas en personajes de novelas cuando su autor es un converso, como en "Varouna" de Julien Green, según él mismo reconocía en su diario: "Mis novelas dejan entrever, en medio de grandes remolinos, lo que yo creo que es el fondo del alma, que escapa siempre a la observación psicológica, la región secreta donde Dios trabajan ${ }^{2}$.

Precisamente por parecerse busca Zambrano las diferencias entre novela y confesión, hallando en primer lugar que mientras la novela nos

2 J. GREEN, Journal (1938-1954) (París: Plon), V, p. 126, 13-XI-1947; cfr. también p. 71, citado y subrayado por Ch. MOELleR, Literatura del Siglo xx y Cristianismo (Madrid: Ed. Gredos, 1961), I, p. 404. 
lleva "a un tiempo imaginario, a un tiempo creado por la imaginación... nos crea otro tiempo... hace nacer en nuestra conciencia otro tiempo. Es otro tiempo que el de la vida" ${ }^{3}$, la confesión "Va en busca, no de un tiempo virtual, sino real" ${ }^{4} \mathrm{y}$, una vez llegado el sujeto a ese momento en el que el tiempo real comienza, percibimos cómo la acción de la confesión "parece ser una acción que se ejecuta no ya en el tiempo, sino con el tiempo, es una acción sobre el tiempo, mas no virtualmente sino en la realidad" 5 . Por eso al formularse se hace la confesión que, siendo una acción cuyo instrumento o medio es la expresión, sólo si se hace en la realidad alcanza a encarnarse como tal expresión. Y es quizá en esto en lo que más se aproxime a esa parte de la literatura que no es ficción sino realidad: la poesía, siempre que emerja de un lugar tan hondo como ésta. Es ese uno de los rasgos o propiedades que la confesión y la poesía, aún siendo diferentes, pudiendo contenerse una en otra, comparten como fenómenos humanos radicalmente verdaderos con aquellos actos humanos que, aun cuando inevitablemente hagan uso de la capacidad humana de simbolización y se encarnen en creaciones simbólicas, como tales actos no están en lugar de nada más que de sí mismos. Su ser está en su hacerse, de modo que o son verdaderos o no son. Ese es el espacio propio de la voluntad (del que nos avisaba Schopenhauer) que toma la representación como instrumento a su servicio para finalmente cumplirse en ella y mostrarse. Su fiabilidad, como señala G. W. Allport al presentar el relato de Frankl sobre su estado de prisión en el campo de concentración de Auschwitz, se aprecia en que "las palabras del Dr. Frankl tienen un tono profundamente honesto, pues se basan en experiencias demasiado hondas para ser falsas" ${ }^{6}$. En coherencia con esto, se decía Unamuno a sí mismo en su diario: "Expón con sinceridad y sencillez tu sentir y deja que la verdad obre por sí sobre la mente de tu hermano; que le gane ella, y no que le sojuzgues tú. La verdad que profieras no es tuya; está sobre tí, y se basta á sí misma" ${ }^{7}$ (sic.). En ese sentido confesión y poesía se acercan en su modo de cumplirse, en su fuerza ejecutiva, en ese modo de probar su verdad que tienen ambas por sus respectivos efectos. Por eso escribir un buen poema o una confesión auténtica sólo puede lograrse mediante una rigurosa fidelidad a la verdad. Quizá

3 M. ZAMBRANO, op. cit., pp. 14-15.

4 Ibid.

5 Ibid, p. 17.

6 V. E. FRANKL, El hombre en busca de sentido (Barcelona: Ed. Herder, 1996), p. 7 [1946].

7 M. Unamuno, op. cit., p. 37. 
también por ello leyendo las Confesiones de S. Agustín podamos apreciar cómo desde el relato de sus culpas, desde la reflexión filosófica o desde la escueta descripción biográfica, Agustín salta con frecuencia en arrebatos poéticos que otorgan a su texto ese talante tan híbrido entre la historia, la filosofía, la teología y la poesía, pero que no es sino el primer modelo de confesión: «iOh verdad, verdad, cuán entrañablemente y de lo íntimo de mi alma suspiraba por Vos, aun en aquel tiempo cuando... en lugar de Vos... me presentaban unas formas brillantes y especiosas,... una comida soñada... y no obstante... aquel manjar soñado... aquellos manjares intelectuales... eran unos cuerpos fingidos y fantásticos... fantasmas enormes e infinitos... Pero Vos, oh amor mío, a quien acudo desfallecido para tener fortaleza... ¡cuán lejos estáis de ser aquellos fantasmas que imaginaba yo mismo!... Vos sois la vida de las almas, vida de las vidas, que vivís por Vos mismo y sin mudanza alguna, oh vida de mi alma!” ${ }^{8}$. Con todo, esa frecuencia con la que S. Agustín culmina pasajes de sus confesiones en una poética oración no identifica, sin más, ambos géneros. En realidad, muchas otras confesiones carecen de similar altura poética. Más allá de esa común fidelidad a una vivencia radical a la que ambas se abren - para que su verdad obre por sí y en cuyo logro poético culminan confesión y poema- hay nuevas condiciones que tipifican la producción de una confesión acercándola a la historia y la etnografía.

Una primera percepción de esta semejanza la podemos encontrar en la sorprendente frecuencia con la que autores como Edith Stein no se limitan a confesar su conversión sino que, por alguna razón, se ven impulsados a narrar una buena parte de su vida, como si conversión y vida se necesitasen mutuamente para poder ambas entenderse. No es esto, por otra parte, una necesidad presente sólo en el autor, sino también en sus lectores. De hecho, muchas de las confesiones han sido escritas a instancia de los futuros lectores. Son los compañeros de Ignacio de Loyola quienes insisten y le asedian durante años para "declarar cuanto por su ánima hasta agora había pasado" y "cómo el Señor le había dirigido" ? También Teresa de Jesús escribe su vida porque "me han mandado y dado larga licencia para que escriba el modo de oración y las mercedes que el Señor me ha hecho... a quien con todo mi corazón suplico, me dé gracia, para que con toda claridad y verdad yo haga esta relación, que mis confesores me mandan" ${ }^{10}$. Tal es también el caso de la Historia de un

8 San Agustín, Confesiones (Madrid: Espasa-Calpe, 1965), pp. 60-61.

9 Prólogos del P. Càmara y del P. Nadal citados por J. M. RamBla en El peregrino. Autobiografía de San Ignacio de Loyola (Bilbao: Mensajero, 1983), pp. 14-15.

10 SAnta Teresa de Jesús, Su vida (Madrid: Espasa-Calpe, 1982), p. 20. 
alma de Teresa de Lisieux. Sin duda, el testimonio vital que la historia de la vida aporta amplía la descripción del proceso de conversión y suministra un panorama de situaciones y experiencias en las que el lector puede buscar semejanzas con las propias, basando en ello los primeros pasos hacia una comprensión.

Pero no sólo es este efecto ejemplar, pedagógico, como lección de la vida que en la vida ajena busca quien pide tal confesión lo que justifica ese más largo despliegue informativo, sino que la conversión misma como hecho histórico reclama la totalidad de la vida del converso como su marco propio, ya que es sobre toda ella, sobre su unidad y sobre la identidad del converso, sobre la que dicho acontecimiento ejerce sus efectos. Si tanto los propios autores, como sus comentaristas, coinciden todos en presentar la conversión como un nuevo nacimiento, refundación o transformación de la persona cuya vida se le transfigura, vida y conversión acaban identificándose formando una unidad, en la cual lo que cada término categoriza (el entramado de los hechos de la vida por una parte y, por otra, los momentos en los que culmina el cambio en su significación) no es sino parte o elemento de un mismo proceso de significación, de creación o innovación de sentido.

Claro está que tal innovación la presenta siempre el autor después de su conversión. No puede el converso prever su conversión, adivinar el final de un proceso no buscado sino sufrido. Esa misma pasividad de la posición del sujeto, su pasión, será también una cualidad que compartirá con la creación artística y que llevará al creyente a atestiguar la presencia de un factor trascendente en el desencadenamiento de su proceso. Esa acción en que la confesión consiste, revela, entre otras cosas, la vivencia en el converso de una acción independiente de su voluntad y que por esa misma independencia prueba su alteridad. Cuenta en una larga carta Simone Weil que en 1937, estando sola en la capilla de Santa María degli Angeli, en Asís, "algo más fuerte que yo me obligó, por primera vez en mi vida, a ponerme de rodillas" ${ }^{11}$. Manuel García Morente, exiliado en París en 1937, escribe en otra carta similar a la de Weil, cómo independientemente de mí, se iba tejiendo, sin la más mínima intervención de mi parte, toda mi vida... Era demasiado evidente que... todo lo...que me estaba sucediendo tenía su origen y propulsión en otro poder bien distinto y harto superior" ${ }^{12}$.

Quedando afectada la vida en su conjunto, y de modo imprevisible, no nos puede extrañar que la confesión vierta hacia dentro y hacia atrás

1 Simone WeIL, A la espera de Dios (Madrid: Ed. Trotta, 1996), p. 41.

12 Manuel García MORENTE, Obras completas II (1937-1942) (Madrid: Anthropos, 1996), vol. 2, p. 421. 
su atenta mirada como otra de las constantes que la caracterizan. El modo de constar ese repaso de la propia historia en el texto es variable. En unos casos es la vida como tal la que aparece desde la infancia (S. Agustín, E. Stein, A. Frossard). En otros, aun cuando se relata la vida, se resume el periodo previo a la conversión para centrarse en la descripción de los efectos posteriores (S. Teresa, S. Ignacio) o, finalmente en otros, el autor deja constancia, repetida incluso pero sin describirla, de la confesión general realizada en el seno de la Iglesia tras la conversión o de las "veces que repasaba en la memoria todo el curso de mi vida" ${ }^{13}$.

No es orgullo narcisista lo que les mueve a efectuar ese examen y recapitulación de toda una vida. Es más, se cambie o no de religión, esa rememoración consta en toda confesión. En realidad la "conversión" parece ser una experiencia de transformación vital en la que el actor sufre una vívida irrupción de la Alteridad Misteriosa, Trascendente y Creadora, oscura y difícil de explicar, pero percibida como radicalmente verdadera y que, precisamente por su evidencia, ilumina toda la vida pasada como algo erróneo, desconocido o fracasado. Es este más amplio sentido de la conversión el que confirman los propios autores de las confesiones, ya que experiencias de ese tipo no son exclusivas de quien por ellas cambia de fe. Así se explica, por ejemplo, que Carlos de Foucauld tras dieciséis años de vida religiosa todavía confiese en varias de sus cartas lo siguiente: "Ruegue por mi conversión... Todo lo que pido es mi conversión, a fin de no ser, por mis infidelidades, un obstáculo...Es menester que yo sea mejor, me convierta, muera, como el grano de trigo" ${ }^{14}$. También el Dr. Frankl tras señalar que, en medio de los duros trabajos de Auschwitz, "Cuando todo se ha perdido... fue entonces cuando comprendí el significado del mayor de los secretos que la poesía, el pensamiento y el credo humanos intentan comunicar: la salvación del hombre está en el amor " ${ }^{15}$, añade cómo "poco después de nuestra liberación, yo paseaba por la campiña florida, camino del pueblo más próximo...; no había nada más que la tierra y el cielo y el júbilo de las alondras, y la libertad del espacio. Me detuve, miré en derredor, después al cielo, y finalmente caí de rodillas. En aquel momento yo sabía muy poco de mí o del mundo, sólo tenía en la cabeza una frase, siempre la misma: 'Desde mi estrecha prisión llamé a mi Señor y él me contestó desde el espacio en libertad'./ No recuerdo cuanto tiempo permanecí allí, de rodillas... Pero yo sé que

\footnotetext{
13 Ibid., p. 418.

14 Jean Francois SIX, Carlos de Foucauld. Itinerario espiritual (Barcelona: Herder, 1978), pp. 238-239.

15 V. FrankL, op. cit., pp. 45-46.
} 
aquel día, en aquel momento, mi vida empezó otra vez. Fui avanzando, paso a paso, hasta volverme de nuevo un ser humano" ${ }^{16}$.

Revelación, desconocimiento de sí mismo, rememoración y renacimiento cuando todo se ha perdido, parecen claros síntomas de una profunda crisis humana que halla finalmente una solución. Si la expectativa de su valor testimonial puede llevar al futuro lector a pedirle al converso su confesión, más allá de esa obediencia, ¿qué lleva al autor a poner también por escrito su confesión, y en qué se centran unos y otros al hacerlo? Ya en la primera de las confesiones reconocía S. Agustín la difícil intelección de lo vivido en la experiencia de una hierofanía: "vi con mi entendimiento vuestras perfecciones invisibles, pero no pude fijar en ellas mi atención, antes bien, deslumbrada la flaqueza de mi vista, y vuelto a mis acostumbrados modos de conocer y pensar, no llevaba conmigo sino la memoria, enamorada de lo que había descubierto, y deseosa de aquel manjar delicioso cuya fragancia había percibido, pero que todavía no podía poseerlo ni gustarlo" ${ }^{17}$. La necesidad de fijar o sujetar esa experiencia, dirá Martín Velasco ${ }^{18}$, es una de las razones. También el orden racional que la escritura exige a la vivencia para que ésta llegue a expresarse, aun cuando traicione la riqueza de su misterio y empobrezca su densidad, precisa y clarifica una parte de lo inefable al ponerla en términos humanos y, con ellos, ayuda a enraizarla en el contexto presente de la cultura contribuyendo a su comunicabilidad y objetivación, facilitando una segunda salida a la soledad del actor que acaba de inaugurar un diálogo con la alteridad del Misterio.

El valor del acto de la confesión o la fuerza de su necesidad, difíciles siempre de medir, pueden quizá apreciarse considerando las dificultades que el converso tiene que superar. Ya vimos la reticencia de Ignacio de Loyola o la escritura por obediencia de Teresa de Jesús, quien reconocía "que muchas cosas de las que aquí escribo, no son de mi cabeza, sino que me las decía este mi maestro celestial... (por lo que) se me hace escrúpulo grande poner o quitar una sola sílaba" ${ }^{19}$. Cabría citar también el "tan profundo pudor y tanta vergüenza" ${ }^{20}$ que el profesor García Morente tuvo que vencer, así como "todos los padecimientos morales que necesariamente mi conversión ha traído consigo, y que no han sido po-

16 Ibid., p. 91.

17 SAN Agustín, op. cit., p. 146.

18 Juan Martín Velasco, La experiencia cristiana de Dios (Madrid: Ed. Trotta, 1996), p. 218.

19 Santa Teresa de Jesús, op. cit., p. 235.

20 M. García Morente, op. cit., p. 438. 
$\cos ^{21}$. Otro indicio, común a todo hecho extraordinario, que igualmente prueba la dificultad sentida al intentar comprenderlo, es la multiplicación de detalles y la densidad de la descripción minuciosa cuando el converso se acerca en su relato a algún punto culminante de su experiencia. No sólo en las visiones o apariciones que los informantes cuentan al antropólogo ${ }^{22}$ se esfuerzan aquellos en sujetar y examinar la imaginación refiriendo lo visto al espacio y tiempo locales, tradicionales. Frossard llega a calificar su confesión "como el atestado de un accidente" ${ }^{23}$ para subrayar cómo es al converso a quien en primer lugar le sorprende el hecho extraordinario.

Pero quizá lo que caracteriza de un modo más claro y común a toda confesión de conversión es aquello en lo que todas se centran: lo que resulta tras ese accidente, y que lleva a quienes lo padecen a someterlo a un duro análisis con la ayuda de la propia escritura y en contraste con la historia, hasta ese momento, de su vida. Si la confesión es un acto, la conversión es una pasión. Si la confesión se despliega en un acto sostenido de escritura, venciendo dificultades íntimas, es en respuesta a la necesidad de reubicar la atención del sujeto que padece los efectos de una honda transformación.

Precedida a veces por circunstancias difíciles, problemas o tensiones que en el papel de antecedentes preconizan una crisis - aunque sólo luego del accidente de la conversión será así reconocido- irrumpe la hierofanía como experiencia radicalmente nueva. Y si bien el converso extraerá de su cultura los términos, categorías y principios religiosos, de la religión que no poseía, para con ellos nombrarla, eso no significa que la experiencia como tal, como hecho ahora vivido, no sea algo absolutamente nuevo. La unanimidad entre los conversos, como constante etnográfica, es clara. Hay un antes y un después, de modo que el conocimiento, ese conocimiento, es vivido como fruto pasivo impuestoporla experiencia sufrida. DeteniéndoseIgnaciodeLoyola enManresa, junto al río Cardoner, señala cómo ase le empezaron abrir los ojos del entendimiento; y no que viese alguna visión, sino entendiendo y conociendo... con una ilustración tan grande, que le parecían todas las cosas nuevas... Y esto fue en tanta manera de quedar con el entendimiento ilustrado, que le parescía como si fuese otro hombre y tuviese otro intelecto, que tenía antes" ${ }^{24}$. Así lo

$21 \quad$ Ibid., p. 439

22 Véase C. LISÓN, La Santa Compaña. Fantasias reales. Realidades fantásticas. (Antropología cultural de Galicia IV) (Madrid: Akal, 1998), en donde el autor aporta abundantísima etnografía sobre el modo como los informantes anclan en el espacio local, en su estructura social, en el tiempo y en las representaciones culturales tradicionales, la creencia que en sus visiones de los muertós se encarna.

23 André Frossard, Dios existe, yo me lo encontré (Madrid: Rialp, 1998), p. 8. 
confiesa Frossard: "Entoncesse desencadena, bruscamente, la serie de prodigios cuya inexorable violencia va a desmantelar en un instante el ser absurdo que soy y va a traer al mundo, deslumbrado, el niño que jamás he sido" ${ }^{25}$. Y García Morente, en su larga carta de confesión, señala cómo aquella experiencia “tuvo un efecto fulminante en mi alma... puesto de rodillas... recordé mi niñez... Es verdaderamente extraordinario e incomprensible cómo una transformación tan profunda pueda verificarse en tan poco tiempo... el hecho es que me veía a mí mismo hecho otro hombre" 26 .

Repasar la vida, rememorarla desde la niñez, no es dolerse ante el hueco o vacío dejado por ese otro hombre ya desvanecido y que lega a quien ocupa su lugar, intacta y entera, intensificada bajo una luz nueva, toda su memoria. Al revés que en la añoranza y la nostalgia, no es un bien lo que se siente como perdido, aun cuando también sea un dolor lo que guíe el análisis de la propia biografía hacia esa más íntima intimidad cuya atención se había perdido. Nuevamente los autores coinciden en categorizar ese doloroso ejercicio como arrepentimiento, usando un término de larga tradición, que en su alta densidad semántica condensa y resume el acto entero de la confesión, todo su proceso, los cambios de posición y la creación de lugares del sujeto, el movimiento de la voluntad, su uso de los valores y el conocimiento que de ese modo se alcanza y no sin él. Así, por ejemplo, al confesar su vida, y hablando como solía por propia experiencia, aconsejaba Teresa de Jesús uestar en soledad, y apartados pensar su vida pasada (lo cual...) todos lo han de hacer muchas veces....... les da pena, que no acaban de entender, que se arrepienten de los pecados" 27 . Confesaba S. Agustín que "por amor de tu amor hago esto trayendo a la memoria con amargura de mi corazón mis torcidos caminos pasados para que tú me veas y me recojas de aquella disipación en que anduve dividido en mil partes, cuando apartado de Ti, Unidad soberana, me disipé entre las criaturas". Quien confiesa, señala Zambrano, "quiere expresarlo para alejarlo y para ser ya otra cosa" ${ }^{28}$, y eso se produce en mayor medida aen momentos en que parece estar en quiebra la cultura... son momentos de crisis... Y así estas Confesiones manifestarán los géneros de fracaso que nuestra cultura ha soportado" ${ }^{29}$.

Sostener ante la mirada la pena, el fracaso o el dolor que se confiesa

\footnotetext{
24 SAN IGNACiO DE LOYOla, op. cit., p. 48.

25 A. Frossard, op. cit., p. 156.

26 M. García Morente, op. cit., pp. 431-432.

27 Santa Teresa de Jesús, op. cit., p. 65.

28 M. ZAMBrano, op. cit., p. 21.

29 Ibid., p. 23.
} 
no responde a morbo masoquista alguno. Más bien nos describe una ancestral estrategia del espíritu humano en la que se nos desvela, una vez más, la unión inescindible entre el lado moral y el lado cognitivo de nuestra condición. Al igual que el dolor en nuestro cuerpo nos avisa y llama nuestra atención dirigiéndola hacia allí donde se detecta un problema, de modo similar ese dolor moral nos ilumina si aprendemos a poner el alma en posición de escucha. Se trata pues de una estrategia de búsqueda en pos de la verdad, adentrándose en el alma de la mano del dolor, disponiéndose a llegar, con toda radicalidad, allí donde tan agudo guía nos lleve. En ese proceso, la hierofanía, aun siendo el fenómeno extraordinario, es sólo un inicio: irrupción de dolor y gozo iniciales con la que el converso se ve movido en una "acción contraria a la del Paraíso" ${ }^{30}$, y en la que convertirse implica que el «alma que se ha encontrado a sí misma recorre en sentido inverso el camino del alejamiento del núcleo más íntimo de sín ${ }^{31}$. Así lo describe Teresa de Jesús: “Estando una vez en oración, se me representó muy en breve... como se ven en Dios todas las cosas, y como las tiene todas en sí... es una de las grandes mercedes que el Señor me ha hecho, y de las que más me han hecho confundir y avergonzar, acordándome de los pecados que he hecho.. Cosa espantosa fué en tan breve espacio ver tantas cosas juntas aquí en este claro diamante, y... ver... cosas tan feas... como eran mis pecados... cuando se me acuerda, yo no sé cómo lo puedo llevar y ansí quedé entonces tan avergonzada, que no sabía me parece adonde me meter" ${ }^{32}$. De modo similar, y tras repasar su vida, García Morente "veía lo infundada que era la especie de satisfacción modorrosa en que sobre mí mismo había estado viviendo; percibía dolorosamente la incurable inquietud e inestabilidad espiritual en que de día en día había ido creciendo mi desasosiego" ${ }^{33}$, añadiendo en su confesión, como ya dijimos, "los padecimientos morales que necesariamente mi conversión ha traído consigo" ${ }^{34}$. De modo más breve confiesa Simone Weil que "en este súbito descenso de Cristo sobre mí, ni los sentidos ni la imaginación tuvieron parte alguna; sentí solamente, a través del sufrimiento, la presencia de un amor análogo al que se lee en la sonrisa de un rostro amado" ${ }^{35}$.

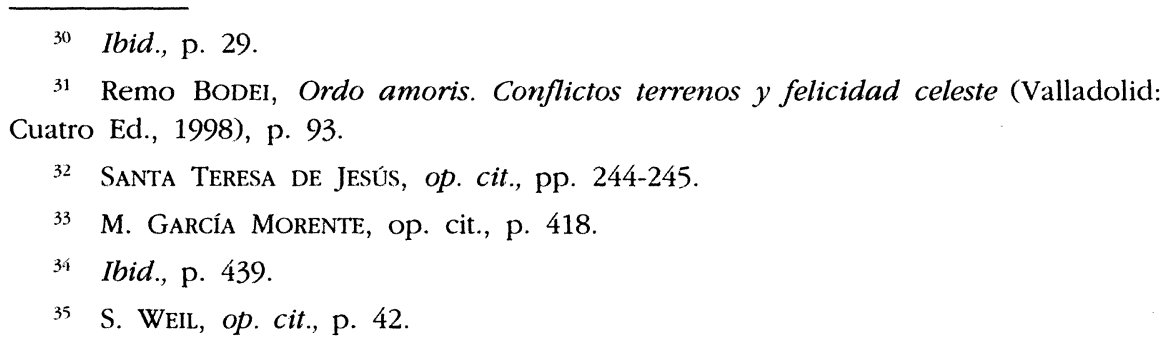


Tras ese impacto inicial, los distintos autores de este tipo de confesiones si asumen el dolor, que toman como guía en la rememoración de su vida, es por su eficacia en la detección de aquellos lugares, en el mapa interior del sujeto, en los que el encuentro entre la vieja imagen propia y lo vivido en la hierofanía, con tan enorme contraste, revela un perfil, un límite en el que resulta inevitable una elección entre dos distintos principios para la conducta, y a los que puede referirse el sujeto identificando con uno u otro su más honda voluntad. La pluralidad de lugares clave con que nos ilustran las confesiones para cartografiar el interior humano quizá sea comparable en su riqueza, en términos morales, a la que en términos biológicos aportan los estudiosos del genoma humano. Llegados a cada uno de tales lugares, con toda la disparidad de cada autor y épo$\mathrm{ca}$, de cada dolor y circunstancia, de nuevo sobresale otra constante etnográfica: la valoración de la humildad como condición indispensable para alcanzar el conocimiento de aquello ante lo cual el dolor, cuya indicación se ha seguido, ha conducido a los autores.

"No cabe desconocer - nos recuerda $M$. Zambrano- que una vida que acata la existencia, la sola existencia de la verdad, es una vida en la que se ha operado algún cambio; es ya una vida transformada, convertida" ${ }^{36}$. Pero lo que aquí garantiza el acceso a la verdad no es la mera racionalidad, la lógica rigurosa o el experimento controlado, sino el radical atenimiento a la alteridad de esa realidad percibida con independencia de la imaginación, memoria y deseo del converso, un atenimiento sin paliativos. Aquí es unánime el parecer de los autores que, por haberla sufrido como experiencia propia, pueden atestiguar la proporcionalidad directa entre el rigor de ese atenimiento y el acceso al conocimiento de lo que en principio no es sino un golpe misterioso y que desencadena dolor y vergüenza. Para encajar el golpe y sostenerlo ante los ojos del alma solo cabe la humildad como valor al que sujetarse, de forma que es ese valor moral el que, al encarnarlo en sí mismo el actor, consigue mover el foco de su atención hacia el punto exacto en el que la realidad se muestra a sí misma en toda su alteridad. Así, reconociendo S. Weil que Dios ejerce sobre el alma uuna presión rigurosa, matemáticamente proporcional a la atención y al amor, (añade que) hay que abandonarse a ese impulso, correr hasta el punto preciso al que nos lleve y no dar un solo paso más" ${ }^{37}$. Por su parte, en una de tan repetidas ocasiones, confiesa S. Agustín cómo sólo en esa sentida interpelación del Misterio la "verdad... levanta hasta sí mismo a los que se le humillan y sujetan" ${ }^{38}$. "Entonces nos sanáis de

36 M. ZAMBrano, op. cit., p. 6.

37 Simone WeIL, op. cit., p. 26.

38 S. Agustín, op. cit., p. 146. 
nuestras malas costumbres, y perdonáis sus pecados a los que humildemente los reconocen y confiesan" ${ }^{39}$. También Unamuno anotaba en su diario que "por la humildad se alcanza la sabiduría... descansando en la verdad y no en la razón. / Entro en la fe con la soberbia de los años... y todo se me vuelve maquinar vanaglorias en ella, haciendo que Dios me sirva y no que sirva yo á El... Pido á Dios que me despoje de mí mismo. / Quisiera no hacer... de la inefable verdad razón sujeta a figuras lógicas..., sino pedir, Señor, que sea santificado vuestro nombre, no con vanas palabras, sino con actos y con palabras que sean actos" ${ }^{40}$, es decir, con lo que Zambrano llama "confesiones".

Entonces ¿qué es lo que estos testimonios nos revelan del valor "humildad» y, de un modo más general, sobre la manera de operar de los valores? En la medida en que no son meros conceptos, ni cobran existencia por la simple operación de formularlos con palabras, sino en tanto que se encarnan configurando acciones, valiendo en ellas, alcanzando su existencia como en tantos fenómenos humanos bajo ese estatuto del gerundio, no podemos sino reconocer que los valores son dinámicos, se despliegan y, en su desarrollo, se transforman a la vez que mueven al sujeto que los encarna, transfigurando su conocimiento de la realidad en la medida en que a ellos se atiene. Son pues muchas cosas a la vez lo que consiguen, y que quizá por darse tan juntas se nos ocultan fácilmente. En realidad hablamos de humildad desde fuera del valor o desde ese momento anterior a aquel en el cual logramos atenernos al valor, ya que una vez se alcanza en la acción moral la humildad se esfuma y desaparece agotándose en su uso como mero signo de la acción que en ese tránsito se realiza. En este sentido, encarnar la humildad -o cualquier otro valor- implica que el sujeto se ha movido entre dos posiciones: la del deber sentido antes de su logro, cuando todavía el sujeto ocupa el lugar que ese golpe de visión de la realidad le ha descubierto (como posición errónea, vana); y la del nuevo lugar o posición alcanzada por el converso y desde la cual sólo cabe percibir la antigua como errónea, orgullosa, fuera de la realidad. Sólo en el tránsito, entre dulce y doloroso, se humilla el converso para acabar no ya en humildad sino en simple realidad. La humildad entonces parece sólo consistir en una realista y esforzada negación de la propia interferencia del sujeto que permite, al olvidarse de sí, la máxima apertura de la atención ante la nueva experiencia para recibir su luz en el conocimiento. Es así como el valor da la clave para el conocimiento: abriendo, enfocando y sosteniendo la aten-

39 Ibid., p. 66.

io M. UNAMUNO, op. cit., pp. 17-18. 
ción, moviendo al sujeto. Por ello nuestras representaciones cambian, se mueven y pluralizan, incluidas aquellas que dan cuenta de nuestra identidad, porque aquello que tienen que representar posee un despliegue y transformación en la biografía y en el espacio interior del sujeto. Algo que, al hablar del proceso creativo, atestiguan igualmente los poetas ${ }^{41}$.

Con todo, aunque efectivamente exista unanimidad en la valoración de la humildad por la eficacia que demuestra, el modo concreto bajo el cual se expresa cambia en la historia. Mientras S. Agustín insiste a lo largo de todas sus Confesiones en la tensión entre verdad y falsedad, realidad y fantasía, amor humilde y orgullo, correlacionando los primeros términos frente a los segundos, S. Teresa de Jesús y S. Ignacio contrapondrán la humildad al honor, insistiendo, junto con S. Juan de la Cruz, en la radicalidad con la que el sujeto ha de determinarse en su anonadamiento. Los conversos contemporáneos, sin embargo, aun cuando también ellos perciben con vigor la relación directa entre humildad y conocimiento, establecen las contraposiciones no tanto frente al honor como frente al trabajo. No sólo es el trabajo al frente de la Facultad de Filosofía uno de los desencadenantes de la crisis de García Morente. Es su confianza en la razón filosófica del determinismo natural ${ }^{42}$, como apoyo vital, lo que entra en crisis tanto o más que la pérdida de su trabajo y la humillación de vivir a costa de otros en su exilio parisino. Por eso, sin duda, y al modo de Unamuno, se pregunta Martín Velasco «qqué le faltaba a Morente para hacer efectiva y reconocer... una presencia de lo religioso?...No le faltaba nada, ...le sobraba el aturdimiento del éxito y la soberbia que cierra el pensamiento del hombre sobre sí mismo" ${ }^{43}$. Ya antes se había quejado Unamuno varias veces en su diario: "Aturdirse en el trabajo; he aquí la última máxima del mundo... ¡Trabajar! ¿Y para qué? ¿Trabajar para más trabajar? ¿Producir para consumir y consumir para producir, en el vicioso círculo de los jumentos?... ipara qué el progreso?... de este progreso, originado de la culpa que trajo el trabajo, se sirve Dios para nuestra salud " ${ }^{44}$, añadiendo poco después cómo una inmensa tristeza se corre por el mundo... es la tristeza del vanidad de vanidades y todo vanidad. La borrachera del progreso cede alguna vez, y los espíritus barruntan el abismo" ${ }^{45}$.

En una época como en otra, los autores plantean en sus confesiones

${ }^{41}$ Véase R. SANMARTín, "Fronteras de la expresión y de la comprensión", Revista de Antropología Social, núm. 3 (1994), pp. 173-196.

42 Véase M. García Morente, op. cit., pp. 423 y 427.

43 J. Martín Velasco, op. cit., p. 229.

4 M. UnAmUNO, op. cit., pp. 46-47.

45 Ibid., pp. 50-51. 
una imagen del valor de la humildad, como instrumento clave para el conocimiento al que llegan, construida frente a aquel otro principio que, resultando central en la configuración cultural de la época (en el caso de los ejemplos: el honor de los siglos de oro, o el trabajo profesional de la modernidad) fracasa en la pretensión, culturalmente sancionada, de condensar una plenitud de sentido para la existencia. Por eso las confesiones, partiendo del íntimo desasosiego producido por esa pérdida de sentido existencial, se nos revelan como una poderosa fuente para la penetración crítica, no sólo en las creencias, sino también en el espíritu de la época; aquel espíritu con el que vistiéndose cada cual ha intentado vanamente poner a salvo su identidad. Como nos recordaba M. Zambrano las confesiones "manifestarán los géneros de fracaso que nuestra cultura ha soportado y... los profundos anhelos encubiertos... y ocultos en la plenitud de los tiempos maduros. Pues cuando el hombre vive en una cultura madura, cuando ha hallado al fin, una objetividad bajo la que habitar, la existencia humana en su desnudez se oculta" ${ }^{46}$.

Ocurre, sin embargo, que aunque la plenitud cultural, su redondez, oculte la desnudez humana y encubra los profundos anhelos del sujeto hipnotizando su conciencia, no por eso dejan de llegar hasta su fondo todos los hechos de su biografía, cuyos ecos morales regresan como sutiles noticias de la flaqueza de toda construcción humana. Por eso, si aún no es excesivo el sueño del siglo - la hipnosis cultural- y todavía queda sensibilidad suficiente como para percibir el roce de esa tan humana fragilidad con la alteridad del misterio, la guía del dolor, tantas veces comentada por los conversos, conduce a esa zona oculta logrando iluminar al menos su superficie. Reconociendo ese "fondo del alma que escapa siempre a la observación psicológican y que J. Green definía como ala región secreta donde Dios trabaja", se preguntaba García Morente si «la transformación (del converso) se va verificando en la subconsciencia desde mucho antes de darse cuenta uno de ella" ${ }^{47}$. Nos describen así los conversos en sus confesiones, como espeleólogos del alma, más y más niveles y estratos del corazón humano, técnicas de inmersión tan inimaginables como el propio dolor, estrategias cognitivas que en realidad son morales y cuya acción consiste en evitarse a sí mismo para conocer.

Con todo, confesaba Edith Stein, "lo que sabemos de nosotros mismos, también acerca de nuestras faltas y yerros, es sólo la superficie iluminada. Lo profundo de donde tales comportamientos brotan, se encuentra ampliamente escondido, incluso para nosotros mismos. Dios lo conoce

46 M. Zambrano, op. cit., p. 23.

47 M. García Morente, op. cit., pp. 431-432. 
y puede purificarlo" ${ }^{48}$. Es decir, que esos hondos niveles a los que con tales estrategias llegan no son, a juzgar por las palabras de todos ellos, todo lo que en el interior del hombre es posible descubrir. Sorprende ver en los autores cuyas confesiones se han estudiado cómo, en un mismo párrafo y sin poder evitarlo, el confeso salta de la descripción a la creación poética y a la oración, del texto dirigido a sí mismo o a un posible lector pasa a una posición distanciada, hablando de sí como si de otro se tratase, llegando a tomar como interlocutor a un Dios trascendente y personal a la vez, como si al llegar a ese más hondo nivel resultase no haber fondo y el sujeto del dolor, saliendo de sí mismo, desapareciese. Quizá por ello el secreto de la confesión no esté para el creyente, como señalaba al principio, sólo en el arrepentimiento, sino que, atendiendo a su perspectiva emic, se añade un nuevo nivel, estrato o dimensión y nos sorprende con algo que parece imposible en la historia: borrar sus huellas, consumir hasta agotar sus efectos devolviendo la inocencia. Además del arrepentimiento está el perdón ${ }^{49}$.

Las confesiones de conversión constituyen un tipo especial de etnografía por su singular sinceridad y por su densidad humana. El análisis de tales crisis descubre en la atención al dolor una estrategia cognitiva eficaz. Comparando confesiones de distintas épocas cabe apreciar la existencia de una tensión relevante entre aquellos valores culturales en los que se centra la configuración del sentido de la vida y la irrupción de vivencias interiores de trascendencia, cuya resolución aparece guiada a través del valor de la humildad. El estudio de todo ello ayuda a comprender el papel que los valores culturales desempeñan en los procesos cognitivos.

Confessions of conversion are a special type of ethnography because of their authenticity and human richness. On analysing those human crisis one realizes that converts pay a rigurous attention to their own spiritual suffering, and use this attention as an efficient cognitive strategy. Confessions from different times are compared to analyse the tension between religious experiences and cultural values related to an ultimate sense for life. The resolution of such relevant tension seems to be guidded by the moral value of humility. The study of that can be useful to understand how cultural values work on cognitive processes.

48 Edith STEIN, Autorretrato epistolar (1916-1942) (Madrid: Editorial de Espiritualidad, 1996), p. 346.

49 Agradezco a la Dra. D. ${ }^{a}$ Blanca Asensi su amable y desinteresada ayuda, las indicaciones bibliográficas y la orientación sugerida para la realización de la investigación. 

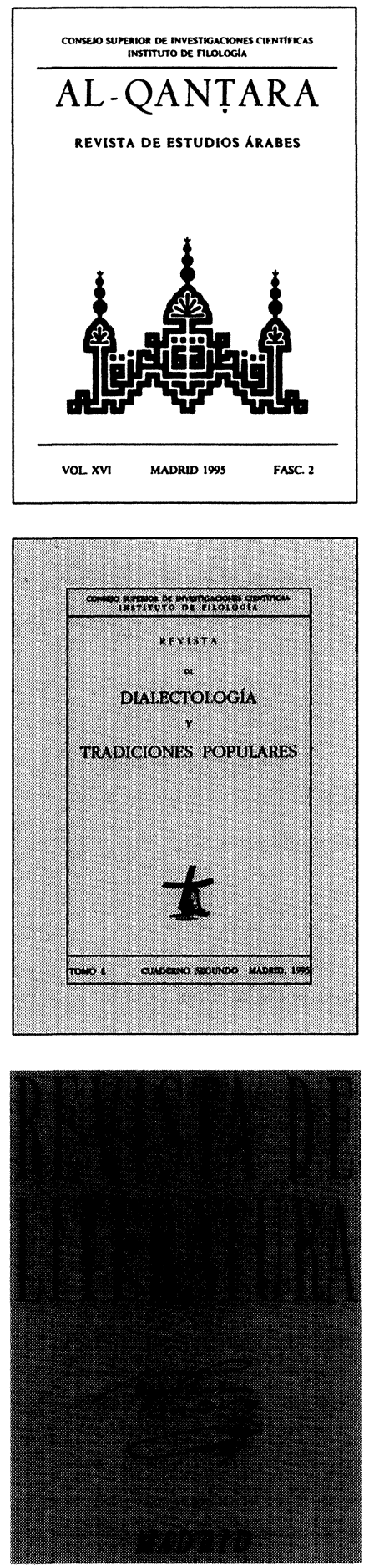
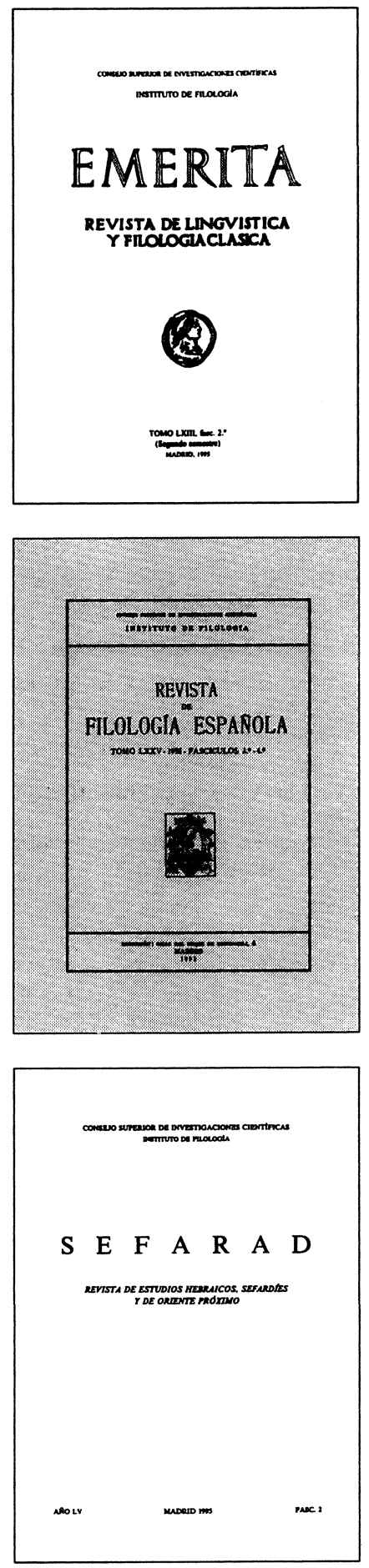